\title{
National culture, entrepreneurship and economic development: different patterns across the European Union
}

\author{
Francisco Liñán* \\ Dept. of Applied Economics. University of Seville \\ Phone: +34-954554487. Fax: +34-954551636. e-mail: flinan@us.es
}

\author{
José Fernandez-Serrano \\ Dept. of Applied Economics. University of Seville \\ Phone: +34-954554344. Fax: +34-954551636. e-mail: jfserrano@us.es
}

\section{Abstract}

The aim of this paper is double. Firstly, it contributes to identifying the specific role of national culture as a variable that helps explain the level of economic development and reinforces the effect of entrepreneurship on the income level. Secondly, a deeper understanding of these relations in the case of the European Union is sought. In this study, data from two different sources have been used. The Schwartz Value Survey (SVS) measures seven cultural orientations that are then grouped into three bipolar dimensions (Embeddedness vs. Autonomy, Hierarchy vs. Egalitarianism and Mastery vs. Harmony). The Global Entrepreneurship Monitor (GEM) provides information regarding entrepreneurial activity.

Using linear regression analysis, cultural and entrepreneurial variables are able to classify countries according to their development level, explaining over $60 \%$ of the variance in GDPpc. The role of culture is complex, with geographical elements being significantly relevant. In the case of Europe, some common elements conform what could be called "a European culture": autonomy and egalitarianism clearly predominate over embeddedness and hierarchy, while harmony tend to prevail over mastery. Nevertheless, four well-defined groups of countries within the European Union emerge. Central and Northern Europe is closer to this European stereotypical culture, while English-speaking countries, Eastern Europe and the Mediterranean area exhibit their own differentiating elements each. These differences also exist with regard to entrepreneurial activity (overall TEA, necessity and opportunity-driven activity). Each of the four regional entrepreneurial cultures is characterized by a different entrepreneurial dynamics that may be plausibly explained by culture and income.

${ }^{*}$ Corresponding author 
Keywords: Entrepreneurship, Cultural values, Economic development, European Union

JEL Codes: A13, L26, R11, O52

\section{Introduction}

Research has shown that there are substantial country differences in entrepreneurial activity (Kelley et al. 2012). This is relevant since entrepreneurs are considered a driving force for innovation, job creation and economic growth (Wennekers et al. 2005; Audretsch 2012). Accordingly, these agents have received increasing attention by policy-makers and also by the academic community. There is, therefore, a great interest in understanding which factors determine the entrepreneurship levels of the different countries or regions.

Previous research in this respect has tended to find a U-shaped relationship between the level of economic activity and that of entrepreneurship (Wennekers et al. 2005; Sternberg and Wennekers 2005; Fritsch and Schroeter 2011). Pinillos and Reyes (2011) have shown that, above certain level of Gross Domestic Product per capital (GDPpc), increased income is associated to higher start-up rates. The reason may be that wealthier countries have a more complex economic system and also a greater demand for new and differentiated consumer goods, both contributing to increased opportunities (Shane 1993).

However, the attempts to explain the level of economic development based on entrepreneurial activity have not been completely successful. Countries with similar income levels exhibit persistent differences in their degrees of entrepreneurial activity (Pinillos and Reyes 2011; van Stel et al. 2005). If the relationship between entrepreneurship and income level is to be fully understood, there is a need to consider the role played by additional variables.

In this respect, the relevant role played by culture in the process of economic development has been stressed (Minkov and Hofstede 2012). In particular, it has been argued that culture may influence the characteristics of prevalent entrepreneurship and, thus, explain its different effect over economic development (Ma and Todorovic 2012). Sociologists and social psychologists have argued that cultural diversity may help explain a wide range of differences in national levels of economic, social, institutional or scientific variables (Inglehart 1997; Hofstede 2003; Schwartz 2004, 2008). Therefore, our first main 
objective is identifying the specific role of national culture as a variable that helps explain the level of economic development and reinforces the effect of entrepreneurship on the income level.

But culture is a multidimensional phenomenon and its impact on economic variables is inherently complex (Schwartz 1999; Hofstede 2003). So far, most contributions have been mainly based on Hofstede's (2003) classification of cultural values. However, concerns have been raised regarding its methodological strength (Jabri 2005; Tang and Koveos 2008). At the same time, alternative classifications have gained relevance. In particular, Schwartz (1992) defines the personal value structure as made up of ten basic universal values. Shared individual values form the basis of the cultural values of a society (Schwartz et al. 2001).

The European Union countries are a very relevant area to carry out this study. It undoubtedly is one of the most advanced economic integration processes in the world. As such, the member states share several common institutions and rules. Besides, despite some differences, all of them are considered high-income economies. However, even in this controlled environment, there is no obvious relationship between entrepreneurial activity and national income levels (Kelley et al. 2012).

Even though some aspects of what may be called a "common European culture" (Schwartz 2008; Ester et al. 1994) distinguish Western Europe from other developed countries, when a closer look is taken, relevant differences between European countries regarding culture do emerge (Schwartz and Ros 1995). In particular, given the shared history, market and institutions, a multidimensional concept of culture is used to capture this cultural diversity. Thus, we specifically argue that cultural differences between EU countries may partly explain the lack of a clear entrepreneurship-income relationship. Therefore, a second objective of this paper is trying to find common patterns among European Union countries with regards to the relationship between entrepreneurship, national culture and development.

This paper is organized as follow: after this introduction, section 2 outlines the relevant theory and the hypotheses derived from it. Section 3 describes the empirical analysis. Results are presented in Section 4 and discussed in Section 5. The paper ends with a brief conclusion.

\section{Theory}

The relationship between entrepreneurship and economic development will be reviewed first. After that, the role of national culture and its relationship to economic development is studied. Thirdly, the interaction 
between culture and entrepreneurship is considered. Finally, the cultural context of European countries is briefly described. Hypotheses are derived in each section.

\subsection{Economic development and entrepreneurship.}

Entrepreneurship plays a very important role in the process of national and regional economic development. It increases employment opportunities, enhances technical innovation level, and promotes economic growth (Reynolds et al. 2002; Fernández-Serrano and Romero 2012). From a dynamic perspective, entrepreneurs are agents of change since entrepreneurship implies starting new businesses, experimenting with new techniques and a new organization of production, introducing new products or even creating new markets (van Stel and Storey 2004; Fernández-Serrano and Romero 2012; Wennekers et al. 2002; Thornton et al. 2011).

Minniti et al. (2006) and Lee and Peterson (2000) found the income level to have an effect on the level of entrepreneurial activity. In particular, the rate of growth in income has been found to have an influence on start-up rates (Armington and Acs 2002; S. Y. Lee et al. 2004). Similarly, when income is measured as GDPpc, the effect on entrepreneurship is positive as well (Parker and Robson 2004; Fishman and SarriaAllende 2004; Audretsch 2012). The level of economic development induces new-firm formation since the environmental opportunities and the expected rewards of starting a business are higher (Reynolds et al. 1994; Fritsch and Schroeter 2011). Individuals may be pulled toward a decision to start a business based on perceived environmental opportunities. At the same time, per capita GDP also influences demand in a specific region, as higher levels of income increase demand and, thus, opportunities for entrepreneurs. Further, there is evidence that the average level of income and wealth determines the variety of consumer demand. A high differentiation in demand favors the suppliers of new and specialized products and diminishes the scale advantages of large incumbent firms (Wennekers et al. 2002; Jovanovic 1993; Fritsch and Schroeter 2011).

However, development might be accompanied by raising real wages. This would increase the opportunity costs of self-employment. Thus, GDPpc could reduce entrepreneurial activity (Noorderhaven et al. 2004; Bjornskov and Foss 2006). This conflicting argument suggests the relationship to be more complex than initially thought. In this sense, some authors (van Stel et al. 2003; Verheul et al. 2002; Liñán et al. 2013) have found a significant positive effect of squared GDPpc, suggesting a U-shaped impact of this income variable 
on entrepreneurship. Thus, for higher levels of income (such as in the EU), a positive relationship between GDPpc and entrepreneurship should be expected (Pinillos and Reyes 2011; Audretsch et al. 2011; Audretsch 2012).

The revised GEM model argues that the contribution of entrepreneurs to an economy changes according to its phase of economic development (Gries and Naude 2008; Kelley et al. 2012). The revised model introduced a more nuanced distinction between phases of economic development (Bosma and Levie 2010; Kelley et al. 2012). When economies are in the innovation-driven stage, as EU countries are, the relationship between entrepreneurial activity and GDPpc is less pronounced. Also, the motivations to start new ventures differ vastly across countries: entrepreneurs in factor-driven economies tend to be equally driven by necessity and improvement-driven opportunity (IDO) motives (Gries and Naude 2008). In contrast, in higher economic development levels, necessity gradually falls off as a motivator, while IDO motives increase (Wennekers et al. 2005; Kelley et al. 2012). That is, necessity motives are impacted by economic conditions. Meanwhile, improvement-driven opportunity motives are less dependent on the economic environment and of a more intrinsic nature, as the individual chooses to pursue an opportunity that is believed to increase income and/or independence.

Based on the theory reviewed above, the following set of hypotheses is formulated to be tested in the empirical analysis

H1a: A negative relationship between entrepreneurship and income exists: low-income countries exhibit higher entrepreneurship rates than high-income countries.

H1b: A positive relationship between opportunity entrepreneurship and income exists: low-income countries exhibit lower opportunity entrepreneurship than high-income countries.

H1c: A negative relationship between necessity entrepreneurship and income exists: low-income countries exhibit higher necessity entrepreneurship than high-income countries.

\subsection{Economic development and Culture.}

However, countries with similar income levels exhibit persistent differences in their degrees of entrepreneurial activity (Pinillos and Reyes 2011; van Stel et al. 2005). In this respect, the relevant role played by national culture in the process of economic development has been stressed (Minkov and Hofstede 2012; Thornton et al. 2011). Cultural diversity may help explain differences in national economic conditions 
(Schwartz 2004; Jaén and Liñán 2013; Schwartz 2008). Therefore, considerable interdependence between culture and economic development should be found (Ros 2002; Mueller et al. 2002; Liñán et al. 2013).

Culture is a complex multidimensional concept, difficult to measure. Inglehart (1997) defines culture as the set of basic common values which contributes to shaping people's behavior in a society. Cultural values operate unconsciously, since they are deeply rooted within the social institutions and technical systems. Therefore, these values and beliefs are continuously reinforced (Pinillos and Reyes 2011). Culture shapes the individual's cognitive schemes, programming behavioral patterns which are consistent with the cultural context (Hofstede 2003; Liñán et al. 2013).

The first and most common classification of national cultures distinguishes between individualist and collectivist ones (Hofstede 2003; Triandis 1995; Schwartz 1999). However, alternative characterizations have also been made. Although Hofstede's cultural dimensions (Hofstede 1991, 2003) have often been used (Li and Zahra 2012), they have been criticized due to methodological weaknesses (Jabri 2005; Tang and Koveos 2008). Thus, in this paper, Schwartz's theory will be followed. It considers cultural values as averaged individual values (Schwartz 1994, 1999, 2004). This theory is strongly based on a universal system of values that guide human behavior. Specific cultural contexts make some of them prevailing over the others (Schwartz 2006a, 2008). This mechanism works through social institutions and their actions (through legislation, government directives, the education system, etc.), selecting and prioritizing some values over the others. In this sense, people tend to carry out what they believe is socially appropriate behavior (Bourdieu 1991; Markus and Kitayama 1991; Schwartz 1994).

At the aggregate level, seven types of national cultural value orientations may be identified (Schwartz 1994): Embeddedness, Intellectual Autonomy, Affective Autonomy, Hierarchy, Egalitarianism, Mastery and Harmony. They may be grouped into three bipolar dimensions (See Figure 1).

- Embeddedness vs. Autonomy (intellectual and emotional): This dimension covers the troubled relationship between the individual and the group. At the embeddedness end, the person is seen as an entity that is included in the community (examples of values may be social order, respect for tradition, family security or wisdom). Meanwhile, at the other end, the person is an autonomous body that finds meaning in his own difference (to be curious, open-minded or creative are values within the intellectual autonomy; pleasure, varied life or exciting life are affective autonomy values). 
- Hierarchy vs. Egalitarianism: The second societal problem is to guarantee responsible behavior that preserves the social fabric. People must be induced to consider the welfare of others, to coordinate with them, and thereby manage their unavoidable interdependencies. It addresses the responsible, cooperative behavior that will get societal tasks done, either by differentiating roles or by internalizing commitment and voluntary cooperation (Schwartz 1994). At the hierarchy end of this dimension, the unequal distribution of power, roles and resources is considered legitimate (social values such as power, authority, humility, wealth). Meanwhile, at the egalitarianism end, the members of society are considered as equal beings who share a commitment to cooperate with others and pursue the common good (social values such as justice, freedom, responsibility, honesty).

- Mastery vs. Harmony: This dimension helps regulate people's treatment of natural and human resources. It solves the problems of the relations between persons, and between person and nature. Those cultures heavily sided towards the mastery pole are seeking personal gain through the exploitation and domination of nature (ambitious, successful, competitive, risk-taker). In the harmony side, instead, cultures that seek individuals fitting harmoniously with nature are placed (unity with nature, protecting the environment, a world at peace...).

Insert Figure 1 around here

The shared and opposing assumptions inherent in cultural values yield a coherent circular structure of relations among them (Schwartz 1999). As shown in Figure 1, the structure reflects the cultural orientations that are compatible (adjacent in the circle) or incompatible (distant around the circle). This conception of cultural dimensions as forming an integrated system, derived from a priori theorizing, distinguishes this approach from others. Thus, Hofstede (2003) conceptualized his dimensions as independent, while Inglehart (1997) derived two broad cultural components empirically.

Regarding the relationship with economic development some patterns have been found. Less developed countries are typically characterized by a predominance of embeddedness and hierarchy, while autonomy and egalitarianism tend to prevail in developed countries (Schwartz 2008). In particular, autonomy seems to be more strongly associated to economic growth, while egalitarianism is more strongly linked to social change 
(Schwartz 2004). Regarding the relationship between mastery/harmony and economic development, a weaker correlation has been found (Schwartz and Ros 1995; Schwartz 2004). This harmony concept has been related to Inglehart's (1997) postmaterialism and is found to be higher in most developed countries. In particular, this cultural orientation is highest in West Europe (Schwartz and Ros 1995), while in English-speaking (especially in the USA) and Confucian countries, mastery is prevalent (Schwartz 2008).

In this respect, the following set of hypotheses about culture en economic development is formulated:

H2a: A negative relationship between the cultural dimension of Embeddedness-Autonomy and income exists:

Embeddedness is prioritized in low-income countries, while autonomy prevails in high-income countries.

H2b: A negative relationship between the cultural dimension of Hierarchy-Egalitarianism and income exists:

Hierarchy is prioritized in low-income countries, while egalitarianism prevails in high-income countries.

H2c: A negative relationship between the cultural dimension of Mastery-Harmony and income exists:

Mastery is prioritized in low-income countries, while Harmony prevails in high-income countries.

\subsection{The interaction between cultural values and entrepreneurship.}

The interrelation between national culture and entrepreneurship is complex (Thurik and Dejardin 2011). Culture may influence entrepreneurship through two main mechanisms (Davidsson 1995). Firstly, a supportive national culture would lead to social legitimation, making the entrepreneurial career more valued and socially recognized, thus creating a favorable institutional environment. More people will therefore try to start their ventures, irrespective of their personal beliefs and attitudes (Etzioni 1987). Secondly, a culture sharing more pro-entrepreneurial values and patterns of thinking would lead to more individuals showing psychological traits and attitudes consistent with entrepreneurship (Fernández et al. 2009; Krueger 2003). Thus, more people will try to become entrepreneurs (Mcgrath et al. 1992; Mueller and Thomas 2001). In this sense, it has been suggested that a high perceived valuation of entrepreneurship in a society will lead to more positive attitudes and intentions by individuals (Fernandez et al., 2009; Liñán et al. 2011).

However, there is evidence to suggest that these relations are not permanent, and change as the level of development increases.Thus, in low income countries, high entrepreneurship coexists with a collectivist culture (Pinillos and Reyes 2011; Wennekers et al. 2007). In turn, in developed countries, higher individualism is associated to increased entrepreneurial activity (Busenitz and Lau 1996; Mueller et al. 2002). In this sense, Schwartz (1999) finds individualism as positively associated to autonomy and egalitarianism, 
while opposed to embeddedness. This result has been confirmed by Ros (2002). Thus, in the case of developed countries with similar levels of income, autonomy and egalitarianism should be positively related to entrepreneurial activity, while the opposed values of embeddedness and hierarchy should be negatively related.

Several recent GEM-based studies have tapped into this interesting area of research. Using this data, Stephan and Uhlaner (2010) perform a cross-country study involving 40 countries and identify two higherorder dimensions of culture -socially supportive culture (SSC) and performance-based culture (PBC). They find entrepreneurship in general to be more influenced by an SSC. With the same GEM-based data, Liñán et al. (2011) showed how individual perceptions about predominant culture have an effect on the person's entrepreneurial intention. Going one step further, Jaén and Liñán (2013) found evidence of the influence of cultural values on entrepreneurial attitudes and intention of individuals.

Therefore, the specific cultural values prioritized in each country will have an effect on the type and level of entrepreneurial activity ( $\mathrm{Ma}$ and Todorovic 2012). In this respect, the differences found in entrepreneurship levels between EU countries (Kelley et al. 2012) should be, at least partly, attributed to cultural differences. In this sense, Bosma and Schutjens (2011) confirm, for a sample of EU countries and regions, that institutional factors still play a role after the effect of economic and demographic attributes is considered.

Therefore, based on this literature, the following general hypothesis about national culture and entrepreneurship is formulated:

H3: There are interrelationships between the national culture and entrepreneurship affecting the income level of countries.

\subsection{Culture, entrepreneurship and economic development in the European context.}

The European Union is a culturally diverse geographic area, with different languages and very varied regional traditions. Of course, considerable differences are also found with respect to income level and entrepreneurial activity. Total Entrepreneurial Activity levels differ widely (from $8.0 \%$ in Greece to $3,7 \%$ in Slovenia). Moreover, the dispersion in GDPpc across the EU Member States remains quite remarkable: Luxembourg has by far the highest GDPpc, more than two and a half times the EU27 average, and about six 
times higher than Bulgaria (the poorest EU Member State) ${ }^{1}$. Despite these differences, the EU has notably advanced towards a single market and several common institutions and policies have been established. It is, therefore, a very relevant group of countries to study the interrrelations between national culture and entrepreneurship in explaining the development level.

Schwartz (2008) discusses the distinctive cultural profiles in each cultural region, reflecting the influence of geographic proximity, history, language, and other factors. According to this author, the culture of West European countries emphasizes intellectual autonomy, egalitarianism, and harmony more than any other cultural region in the world. In this region, the priority attached to hierarchy and embeddedness is the lowest. This profile holds even after controlling for national wealth. Compared with other world regions, West European countries share a broad culture (Ester et al. 1994; Schwartz and Ros 1995).

Still, there is variation within the continent. For instance, the Greek culture is lower on intellectual autonomy and egalitarianism than the other West European countries, while France displays a relatively high hierarchy orientation for Western Europe (Schwartz 2008). In contrast, Ireland and the UK are grouped together with other English-speaking countries, and apart from the rest of Europe. These countries are especially high in affective autonomy and mastery compared with the rest of the world, pointing to a cultural orientation that encourages an assertive, pragmatic, entrepreneurial and even exploitative orientation to the social and natural environment (Schwartz 2008). With regard to East European cultures, they are higher on embeddedness and hierarchy than Western Europe and the USA, although lower on these cultural orientations when compared with less developed countries in Africa, Asia and the Middle East.

To summarize, there are notable differences in national culture by country, which are reflected on income levels and entrepreneurial activity. In this context, the present study will identify common patterns between European Union countries with regard to national culture and entrepreneurship.

Based on this classification, the types and characteristics of the predominant entrepreneurial activity in each country are likely to vary (Bosma and Schutjens 2011). In a recent study, Liñán et al. (2013) found the empirical support for the following relationships in higher income countries, such as those in the European Union: higher autonomy and egalitarianism are correlated to higher entrepreneurship rates. Similarly,

\footnotetext{
${ }^{1}$ Eurostat: Statistic in focus $64 / 2011$.
} 
egalitarianism was also related to the ratio of opportunity to necessity entrepreneurship. Regarding the mastery-harmony dimension, they argue that mastery promotes entrepreneurship in general (irrespective of income level and of type of motivation).

Therefore, different combinations of these three cultural dimensions, should lead to alternative combinations of opportunity and necessity entrepreneurship, as well as to different overall entrepreneurial activity levels. In particular, Continental, English-speaking and East European countries would clearly differ in their cultural configuration and, through it, in their patterns of entrepreneurial activity. Thus, the following hypotheses are formulated:

H4: The relationship between the cultural dimension of Mastery-Harmony and the income level is different in Western Continental Europe from that in other high income countries: It is positive in general, but negative for Continental Europe..

H5: Three different models of national culture and entrepreneurship rates affecting income levels exist in Europe (Continental, English-speaking and East Europe): significant differences exist between them with respect to culture, entrepreneurship and income levels.

Figure 2 summarizes the proposed model and the hypotheses to be tested.

Insert Figure 2 around here

\section{Empirical analysis}

The empirical analysis will be carried out on a sample of developing and developed countries. In particular, special attention will be paid to the case of the European Union. Of the total sample of 56 countries, 27 are developed and the rest (29) developing. Within the European Union, 19 countries are included in the sample (all of them considered as developed): Austria, Belgium, Denmark, Finland, France, Germany, Greece, Hungary, Ireland, Italy, Latvia, Netherlands, Portugal, Poland, Slovenia, Romania, United Kingdom, Spain and Sweden. 


\subsection{Methodology}

The empirical analysis will be divided into two phases. Firstly, linear regression analysis will be used to classify countries according to their GDPpc level. The explaining variables will be entrepreneurial activity and cultural variables. This should serve to test whether hypotheses H1a-c, H2a-c, H3 and H4 hold. Secondly, a cluster analysis will be performed with European Union member states. In this case, cultural variables, entrepreneurial activity and income level are used together as classifying variables. The resulting classification and its significance (measured through ANOVA tests) will serve to test hypothesis H5. The selection of countries has been made based on the available data (countries participating in both the GEM project and the SVS study were included). Overall, a sufficiently large data set is used, as compared with other similar studies (van Stel et al. 2007; Pinillos and Reyes 2011). Three kinds of variables are therefore used in this analysis, coming from three different sources (World Bank for income, GEM Project for entrepreneurship and Schwartz's Value Survey for cultural values):

- For income level, Gross Domestic Product per capita will be used, as done often in this type of research (Wennekers et al. 2007; Carree and Thurik 2008; Pinillos and Reyes 2011).

a) Gross Domestic Product per capita (GDPpc). Data are obtained from the World Development Indicators of the World Bank (average for the period 2001-2011).

- For entrepreneurship, data come from the Global Entrepreneurship Monitor (GEM) statistics ${ }^{2}$. Since 1999, the GEM project measures and compares the entrepreneurship levels for different time periods and countries. The more general Total Entrepreneurial Activity (TEA) is used, together with entrepreneurial motivations, following the GEM project definitions:

b) Total Entrepreneurial Activity (TEA): percentage of 18-64 population who are either a nascent entrepreneur (starting a venture, or just started one with no more than 3 months of existence) or owner-manager of a new business (i.e., owning and managing a running business that has paid salaries, wages, or any other payments to the owners for more than three months, but not more than 42 months). The values are averaged annual data for the period 2001-2011.

c) Necessity-Driven Entrepreneurial Activity (TEA-Necessity): Total Entrepreneurial Activity reporting necessity as major motive, i.e. percentage of 18-64 population who are pushed into starting

\footnotetext{
${ }^{2}$ Available from the GEM consortium web page: http://www.gemconsortium.org/key-indicators.
} 
businesses out of necessity because they have no other work options and need a source of income. The values are averaged annual data for the period 2005-2011.

d) Improvement-Driven Opportunity Entrepreneurial Activity (TEA-Opportunity): Total Entrepreneurial Activity reporting opportunity as major motive (either (i) they claim to be driven by opportunity as opposed to finding no other option for work; and (ii) indicate the main driver for being involved in this opportunity is being independent or increasing their income, rather than just maintaining their income). The values are averaged annual data for the period 2005-2011.

- For cultural values, the Schwartz Value Survey (SVS) will be used (Hebrew University). The Schwartz Value Survey consists of 57 Items. They represent 7 value orientations on the national cultural level. The data are available for more than 60 countries during the period 1985-2005. The average for each country has been computed for the 57 value-items. These regional-level scores were them averaged into seven cultural orientations (Schwartz 2004; Schwartz and Ros 1995). Finally, the seven cultural values were grouped again into three bipolar cultural dimensions, by subtracting the score in the second cultural value (autonomy, egalitarianism and harmony) from the score in the first (embeddedness, hierarchy and mastery), as indicated by Schwartz (2006b, 2008). These three dimensions will be the variables for our empirical analysis:

e) Embeddedness vs. Autonomy ${ }^{3}$ (Emb-Auto): A positive value represents predominance of the embeddedness element, whereas a negative value reflects the predominance of the autonomy element. Average 1985-2005.

f) Hierarchy vs. Egalitarianism (Hier-Egal): A positive value represents the predominance of hierarchy values, whereas a negative value reflects the predominance of egalitarianism. Average 1985-2005.

g) Mastery vs. Harmony (Mas-Har): A positive value reflects the predominance of the first element (mastery), whereas a negative value represents the predominance of harmony values. Average 19852005.

h) Mastery vs. Harmony in West European Countries (Mas-Har_Europe). A dummy variable was created to specifically evaluate the impact of the "Mas-Har" cultural dimension in West European Countries. This variable is the result of multiplying the previous "Mas-Har" variable by the WestEurope Dummy (value 1 for Western Europe -except English-speaking countries- and 0 for all

\footnotetext{
${ }^{3}$ Autonomy being the average of intellectual and affective autonomy.
} 
others). The countries included in Western Europe are chosen following Schwartz (2008): Austria, Norway, Switzerland, Belgian, Denmark, Finland, France, Germany, Greece, Ireland, Italy Netherlands, Portugal, Spain and Sweden. This variable will capture the specific differential effect of the Mas-Har cultural dimension in the case of Western Continental Europe.

Table 1 shows the correlations between these variables. As may be seen, the correlation between GDP per capita and TEA is very high, since the entrepreneurial activity (TEA) diminishes as income grows $(-0.615$, $\mathrm{p}<0.01)$. The same applies to the levels of TEA-Necessity (-0437) and TEA-Opportunity (-0689). Therefore, preliminary support is found for Hypotheses $\mathrm{H} 1 \mathrm{a}$ and $\mathrm{H} 1 \mathrm{c}$, but not for $\mathrm{H}_{1} \mathrm{~b}^{4}$. Table 1 provides some initial support to Hypotheses $\mathrm{H} 2 \mathrm{a}, \mathrm{H} 2 \mathrm{~b}$ and $\mathrm{H} 2 \mathrm{c}$, since the correlations between GDPpc and the cultural dimensions are negative and significant. That is, higher GDPpc is clearly associated to an emphasis in autonomy and egalitarianism values (correlation of Emb-Auto and Hier-Egal to GDPpc is -0.716 and -0.523 , respectively, $\mathrm{p}<0.01)$. The relationship to the mastery-harmony dimension, in turn is not so general. Higher income is associated to a predominance of harmony in Western Europe $(-0.435, \mathrm{p}<0.01)$, but not for the rest of the world (-0.246, not significant).

Insert Table 1 around here

\section{Results}

Five linear regressions were run using the ordinary least squares method for estimations (see Table 2). In all instances, the variance inflation factors (VIF) and the condition indexes (CI) indicate that multicollinearity is not a problem in these regressions. The highest condition index is 5.22 and the highest VIF is 2.66 , this being observed for the variable "Hier-Egal" in the third model. Similarly, all variables have been checked for normality with a Kolmogorov-Smirnof test. No evidence of first order linear auto-correlation was found in our multiple linear regression data (Durbin-Watson statistic is close to 2.0 for all the models), and the

\footnotetext{
${ }^{4}$ Total TEA-Opportunity is negatively related to income, but the ratio of opportunity to necessity exhibits a positive relationship. In this sample, the Pearson's correlation between the ratio TEA-Opportunity/Necessity and GDPpc is positive and significant $(0.672 * *)$.
} 
residuals are normally distributed, according to the normal probability plot. Finally, Levene's test was used to confirm the equality of variances. The models explain a satisfactorily high percentage of the variance in GDPpc, ranging from 37.8\% in Model 1, to 66.1\% in Model 5. The great majority of variables are significant. Table 2 shows the main results for the models.

In Model 1, entrepreneurship alone is used to explain GDPpc. It accounts for $37.8 \%$ of the variance in the income level. The coefficient is negative and highly significant $(-0.615, \mathrm{p}<0.001)$, thus supporting hypothesis H1a. Model 2 includes the three cultural variables as explanatory variables. The results offer support for hypotheses $\mathrm{H} 2 \mathrm{a}$ and $\mathrm{H} 2 \mathrm{~b}$, but not for $\mathrm{H} 2 \mathrm{c}$ (the Mas-Har $\beta$ coefficient is not significant). This second Model also offers partial support from hypothesis H3; since the coefificent for TEA changes substantially when cultural variables are included, providing evidence of interrelation between these variables. However, the 95\% confidence intervals (C.I.) for $\beta_{\mathrm{TEA}}$ do not allow a full confirmation of H3. In Model 1, the original (unstandardized) $\beta$ equals -1.057 , while in Model $2 \beta$ is -0.560 , but the C.I. are, respectively, $(-1.426,-0.687)$ and $(-0.950,-0.170)$. The overlap between both C.I. implies the possibility that the true value remains the same in both models. Therefore, H3 is not confirmed.

In Model 3, the dummy variable Mas-Har-Europe is added to test hypothesis H4. Doing so, a clearer pattern emerges. In general, the prevalence of Mastery values is associated to higher income. But, in Continental Europe the opposite relationship is found ${ }^{5}$.

Models 4 and 5 serve to test hypothesis H1b and H1c. As may be seen, they are both supported. In Model 4, once TEA is taken into account, the effect of TEA-Opportunity is positive and significant $(0.397$, $\mathrm{p}<0.001$ ), thus supporting hypothesis $\mathrm{H} 1 \mathrm{~b}$. In model 5, in turn, TEA-Necessity absorbs all the effect of entrepreneurship on GDPpc, making the TEA coefficient non-significant. Nevertheless, support can still be claimed for hypothesis H1c, since the coefficient for TEA-Necessity is negative and significant $(-0.461$, $\mathrm{p}<0.001)$.

Insert Table 2 around here

\footnotetext{
${ }^{5}$ More precisely, the effect in Continental Europe is the addition of both coefficients ( $\beta_{\text {Mas-Har }}+\beta_{\text {Mas-Har-Europe }}$ ). Therefore, in Model 3, the effect of Mas-Har for these European countries is $0.060(=0.288-0.228)$, while in Models 4 and 5 is, respectively, $0.094(=0.321-0.227)$ and $0.033(=0.283-0.250)$.
} 
The second stage of the empirical analysis consists on testing the existence of three different patterns of relationships between cultural and entrepreneurial variables in the European Union. For the purpose of the cluster analysis, the three cultural dimensions have been used to classify the countries into homogeneous groups. Two cluster procedures were applied, including hierarchical cluster and a K-Means Clustering procedure. The dendogram showed five main groups of countries which were confirmed by K-Means Clustering and ANOVA analysis. These analyses confirm the results' robustness. However, Romania was repeatedly classified alone as a 1-unit group. Having entered the EU so recently (2007) and its income level being substantially lower than any other EU country (except Bulgaria), it can clearly be considered an outlier. For this reason it was eliminated from the analysis. For the remaining 18 countries, the final clusters are presented in Figure 3 and their centers are shown in Table 3.

Insert Table 3 around here

Insert Figure 3 around here

Insert Table 4 around here

Overall, the results of the cluster analysis serve to confirm hypothesis H5, at least partially, since four clearly different groups of European countries emerge. Three groups were expected, but the largest of them (Western Continental Europe countries) is divided into two categories: Mediterranean (Portugal, Spain, 
Slovenia and Greece) and the rest ${ }^{6}$. From a geographical perspective, the four clusters can be described as follow (see Figure 3 and Table 4):

a. Cluster 1: English-speaking countries. This area includes both countries in the British islands. This cluster has a high GDP per capita. These countries are characterized by the predominance of autonomy, egalitarianism and mastery. The highest levels of TEA and opportunity-led entrepreneurship are found here, together with an average level of necessity-driven entrepreneurship.

b. Cluster 2: Eastern European countries. This area is describing former communist states. These countries are characterized by relatively low GDPpc. Its main cultural profile is characterized by lower levels of autonomy and egalitarianism. Harmony still predominates (although weakly). These countries present the highest level of necessity entrepreneurship, but also a quite high level of opportunity entrepreneurship.

c. Cluster 3: Mediterranean Countries. This area is culturally similar to Cluster 4 in egalitarianism and harmony, but exhibits a relatively lower prevalence of autonomy. Their income level is also lower. Regarding entrepreneurial activity, TEA is not so high as in cluster 1, because opportunity-driven entrepreneurship is lower, while TEA-necessity is similar,

d. Cluster 4: North and Central European Countries. This area is associated with developed countries in the center and north of Europe. This group has a high level of autonomy while the prevalence of egalitarianism and harmony is the strongest. This area has the lowest levels of overall TEA, opportunitydriven and necessity-led entrepreneurship.

\section{Discussion}

Over a sample of developed and developing countries, this paper uses a multidimensional concept of culture to help explain the complex relationship between culture, income and entrepreneurship. The three entrepreneurial variables, and the three cultural dimensions, are all significant in explaining income differences by country ( $\mathrm{H} 1$ and $\mathrm{H} 2)$. In the specific case of Europe, four regions sharing cultural and

\footnotetext{
${ }^{6}$ In this sense, it is interesting to note that, when 5 groups are forced, the only difference is that the new group includes France, Italy and Spain. This would confirm the existence of a Center-North group of countries, and a Mediterranean one. The large Latin countries would share characteristics of both (Spain being closer to the southern group, while Italy and France closer to the northern one). Both alternatives are supported by the ANOVA test, but the 4-cluster solution is more parsimonious. For that reason, it has been chosen.
} 
entrepreneurial characteristics are found (H5). Therefore, national culture and entrepreneurship can jointly help characterize the level of economic development in terms of GDPpc (H3).

With respect to the entrepreneurship variable TEA, our results confirm once more the presence of a global negative relationship between the income level and TEA when countries of different levels of development are compared (Reynolds et al. 2002; Kelley et al. 2012). Nevertheless, since TEA is an aggregated measure, it may be more difficult to predict. In turn, entrepreneurial activity out of specific motives (TEA-necessity or TEA-opportunity), may be more clearly linked to culture and/or income. In fact, in Table 3, there is no obvious pattern regarding the differences in overall TEA. TEA-necessity, in turn, is highest in Eastern Europe and the poorer countries in the Mediterranean area (cluster 3). Thus, necessity motives seem to be more directly connected with the economic situation; as this latter element improves, alternative employment options are available and the need to start a venture is lower. Even in developed countries such as the European Union, the relation holds (as seen by comparing the clusters).

In contrast, TEA-opportunity is quite stable across countries, ranging from 2.5 to 3.9. Nevertheless, a stronger emphasis in mastery (or weaker in harmony) appears to explain this variation. As explained above, opportunity entrepreneurship does not depend so much on the economic situation, but more on the acceptable ways to thrive and achieve personal self-objectives. In this sense, countries where mastery is combined with a high emphasis on autonomy may be providing an especially favorable environment for entrepreneurship. This is the case of the English-speaking countries. Thus, UK and Ireland have a similar income level and prevalence of autonomy than those of Central and Northern Europe (cluster 4). But they have a much higher TEA rate ( 7.2 vs. 4.5$)$, and also TEA-Opportunity (3.9 vs. 2.6). One possible explanation is that, given a certain level of income, a culture emphasizing autonomy encourages individuals to care about their own needs, while mastery legitimizes the active (and even aggressive) search for personal improvement (Schwartz 2008). Since a high-income economy provides for plenty of opportunities, there will be more people trying to start their ventures. In central and northern Europe, instead, society stresses autonomy and people are therefore entitled to satisfy their own needs. But the predominance of harmony makes them be concerned about congenial agreement with others and maybe not so worried about economic/materialistic rewards, or self-promotion. Besides, this emphasis in harmony values has probably contributed to the development of a more generous welfare state, leading to a lower need for starting up as a means of survival. 
These findings partly support the well-known argument by Max Weber (1905) that shared religious values explain economic behavior of individuals. Religion has long been a very important element shaping cultural values. Weber's theory broadly holds if we refer to economic development in general, since predominantly protestant countries are among the most developed in the world. However, when entrepreneurship is specifically considered, the argument is weaker. Protestant countries in continental Europe exhibit substantially lower entrepreneurial activity than those of English-speaking countries. However, more than a century has passed since the publication of that work: the economic situation has changed notably, and history has left its mark.

Related to this, the diverging characteristics of Western Continental Europe regarding the emphasis on harmony, and its influence on the income level, deserve closer attention. Unfortunately, no comparable cultural characterization of European countries at the beginning of the $20^{\text {th }}$ century exists. But, most probably, events throughout the century have contributed to a change in cultural values towards stressing harmony (World War II, Holocaust, Cold War, Welfare State). Stressing this cultural value, in turn, may have had as an unintended consequence, a lower level of entrepreneurial activity in Central and Northern Europe.

This is a clear indication that culture is a complex phenomenon that cannot be accounted for by the simplistic distinction between individualism and collectivism. Much is yet to be known regarding the way in which cultural values influence entrepreneurial activity. According to Schwartz (2006), this influence would take place through social institutions (social legitimation, in the words of Davidsson, 1995). The present study offers relevant indications that the relationship exists, but additional work is needed to better understand the mechanisms through which it takes place. Overall, the results suggest that there is not one single cultural profile for developed countries. Thus, in continental Europe, higher development is associated to a stronger emphasis on harmony values. In contrast, in the rest of the world, mastery may be compatible with higher income.

In this paper, culture has been considered as a national level variable. However, it may be defined at less aggregated levels (Fayolle et al. 2010), In this regards, there is some evidence that geographical, political, historical and economic proximity play a role in the configuration of cultural values. Thus, the grouping of countries based on cultural similarities (Schwartz 2008; Hofstede 2003) exhibit a clear geographical pattern. Similarly, there is evidence that national culture is a meaningful concept (Minkov and Hofstede 2012). In this regard, therefore, the use of national level data for cultural values is justified. 
This does not mean, however, that there are no intra-country variations in culture. In countries with substantial regional diversity (such as Belgium or Italy, for instance), internal differences in culture may be relevant. Additionally, the presence of ethnic groups or minorities (notably immigrants) would also imply the possibility of different subcultures. In this sense, the study of shared values in different groups of the population may prove very relevant. The interplay between the wider national culture and the more restricted group-culture may lead to specific entrepreneurial patterns of behavior.

Another element that deserves attention is the modification of cultural values. Culture is not permanent (Mcgrath et al. 1992), even though if it changes only slowly, over long periods of time. In the particular case of the European Union, internal mobility has grown notably thanks partly to increased integration and some institutional measures (such as the Erasmus student exchange program, for instance). The consequences that increased mobility may have on the convergence of national cultures in Europe also deserve attention.

Of course, the present study presents some limitations regarding the availability of data, and the impossibility to derive casual relationships from it. In forthcoming studies, the U-shaped relationship between entrepreneurship and income should be tested within this framework. Similarly, the explanations suggested here also need to be confirmed in future research. The present study is of a more explorative nature with respect to the possible interrelations between cultural dimensions and entrepreneurship. Nevertheless, the authors believe it opens some interesting avenues of research about the relative combination of cultural dimensions and its effect on entrepreneurship.

\section{Conclusion}

This paper has shown that cultural values and entrepreneurship are sufficiently descriptive of an economy to allow identification of its income or development level. A multidimensional concept of culture has been used here, with three bipolar dimensions. This is not to say that GDPpc is determined by cultural and entrepreneurial variables alone. The cross-sectional nature of this study does not allow it. However, the deep interrelations between cultural variables, economic elements and entrepreneurial activity are confirmed.

In the case of Europe, an apparently integrated and culturally similar continent, several significant differences are found with respect to these three groups of variables (income, entrepreneurship and culture). 
At least four different "entrepreneurial cultures" are found: the Central/North, the British Isles, the Mediterranean and Eastern Europe. The motives and conditions to start a venture may be notably different in each area, and culture is deemed to be one of the key elements explaining the differences.

The implications of these results are wide. In the first place, further studies along these lines will shed additional light on the specific interrelations between culture and entrepreneurship. Logic has led us to interpret that cultural values condition the (entrepreneurial) behaviors of individuals. That is, the environment influences personal behaviors. Nevertheless, the possibility that entrepreneurial activity may lead to cultural change should also be explored. Secondly, a deeper knowledge about these interrelations will undoubtedly serve to better understand entrepreneurship. In this way, specific programs and measures could be designed to take into account the specific cultural characteristics of the environment where they are to be implemented.

A number of valuable avenues for future research are opened from this study. The interplay between different levels of culture and how it affects entrepreneurship is one of them. Similarly, cultural change also deserves attention; notably, the entrepreneurial cultures and behaviors of young vs. older groups of the population. The influence of culture on entrepreneurial motivations is also of interest, as is also the change in those relationships as the level of economic development of the country increases,

\section{Acknowledgements}

The authors are most grateful to the Editors and to three anonymous reviewers, whose comments and suggestions have contributed to improve the quality of this paper. Of course, any errors that remain are the sole responsibility of the authors.

\section{References}

Armington, C., \& Acs, Z. J. (2002). The Determinants of Regional Variation in New Firm Formation Regional Studies, 36(1), 33-45.

Audretsch, D. B. (2012). Entrepreneurship research. Management Decision, 50(5), 755-764, doi:10.1108/00251741211227384.

Audretsch, D. B., Aldridge, T. T., \& Sanders, M. (2011). Social capital building and new business formation. International Small Business Journal, 29(2), 152-169, doi:10.1177/0266242610391939. 
Bjornskov, C., \& Foss, N. J. (2006). Economic freedom and entrepreneurial activity: Some cross-country evidence. DRUID Working paper, 06-18.

Bosma, N., \& Levie, J. (2010). Global Entrepreneurship Monitor: 2009 Executive Report. http://www.gemconsortium.org/. Accessed October 2011.

Bosma, N., \& Schutjens, V. (2011). Understanding regional variation in entrepreneurial activity and entrepreneurial attitude in Europe. The Annals of Regional Science, 47(3), 711-742, doi:10.1007/s00168010-0375-7.

Bourdieu, P. (1991). Language and Symbolic Power. Cambridge: Polity Press.

Busenitz, L. W., \& Lau, C. M. (1996). A cross-cultural cognitive model of new venture creation. Entrepreneurship Theory and Practice, 20(4), 25-39.

Carree, M. A., \& Thurik, A. R. (2008). The lag structure of the impact of business ownership on economic performance in OECD countries. [Article]. Small Business Economics, 30(1), 101-110.

Davidsson, P. (1995). Culture, structure and regional levels of entrepreneurship. Entrepreneurship and Regional Development, 7(1), 41-62.

Ester, P., Halman, L., \& Seuren, B. (1994). Environmental concern and offering willingness in Europe and North America. In P. Ester, L. Halman, \& R. de Moor (Eds.), The individualizing society: Value change in Europe and North America (pp. 163-181). Tilburg: Tilburg University Press.

Etzioni, A. (1987). Entrepreneurship, adaptation and legitimation: a macro-behavioral perspective. Journal of Economic Behavior \& Organization, 8(2), 175-189.

Fayolle, A., Basso, O., \& Bouchard, V. (2010). Three levels of culture and firms' entrepreneurial orientation: A research agenda. Entrepreneurship and Regional Development, 22(7-8), 707-730.

Fernández-Serrano, J., \& Romero, I. (2012). Entrepreneurial quality and regional development: Characterizing SME sectors in low income areas. Papers in Regional Science, doi:10.1111/j.14355957.2012.00421.x.

Fernández, J., Liñán, F., \& Santos, F. J. (2009). Cognitive Aspects of Potential Entrepreneurs in Southern and Northern Europe: an Analysis Using Gem-Data. Revista de Economía Mundial, 23, 151-178.

Fishman, R., \& Sarria-Allende, V. (2004). Regulation of entry and the distortion of industrial organization. Working Paper No. 10929. Cambridge, MA: National Bureau of Economic Research.

Fritsch, M., \& Schroeter, A. (2011). Why does the effect of new business formation differ across regions? Small Business Economics, 36(4), 383-400, doi:10.1007/s11187-009-9256-9.

Gries, T., \& Naude, W. (2008). Entrepreneurship and Structural Economic Transformation (Working Paper RP2008/62). Helsinki: UNU World Institute for Development Economics Research (UNU-WIDER).

Hofstede, G. (1991). Cultures and organizations: software of the mind. London: McGraw-Hill.

Hofstede, G. (2003). Culture's consequences: comparing values, behaviors, institutions and organizations across nations (2nd edition ed.). Newbury Park: Sage Publications.

Inglehart, R. (1997). Modernization and Postmodernization. Princeton: Princeton University Press.

Jabri, M. M. (2005). Commentaries and critical articles: Text-context relationships and their implications for cross cultural management. International Journal of Cross Cultural Management, 5(3), 349-360.

Jaén, I., \& Liñán, F. (2013). Work values in a changing economic environment: the role of entrepreneurial capital. International Journal of Manpower, 34, In press. 
Jovanovic, T. B. (1993). The Diversification of Production. Brookings Papers on Economic Activity, Microeconomics, 1993(1), 197-235.

Kelley, D. J., Singer, S., \& Herrington, M. (2012). GEM 2011 Global Report: Global Entrepreneurshiop Research Association (GERA).

Krueger, N. F. (2003). The cognitive psychology of entrepreneurship. In Z. J. Acs, \& D. B. Audretsch (Eds.), Handbook of entrepreneurship research: An interdisciplinary survey and introduction (pp. 105-140). London: Kluwer.

Lee, S. M., \& Peterson, S. J. (2000). Culture, entrepreneurial orientation, and global competitiveness. Journal of World Business, 35(4), 401-416.

Lee, S. Y., Florida, R., \& Acs, Z. J. (2004). Creativity and entrepreneurship: A regional analysis of new firm formation. Regional Studies, 38(8), 879-891.

Li, Y., \& Zahra, S. A. (2012). Formal institutions, culture, and venture capital activity: A cross-country analysis. Journal of Business Venturing, 27(1), 95-111, doi:http://dx.doi.org/10.1016/j.jbusvent.2010.06.003.

Liñán, F., Fernández, J., \& Romero, I. (2013). Necessity and opportunity entrepreneurship: The mediating effect of culture. Revista de Economía Mundial, 33, 27-51.

Liñán, F., Santos, F. J., \& Fernández, J. (2011). The influence of perceptions on potential entrepreneurs. International Entrepreneurship and Management Journal, 7(3), 373-390.

Ma, J., \& Todorovic, Z. W. (2012). Understanding the role of entrepreneurial quality and national culture on the economic development. International Journal of Entrepreneurship and Small Business, 16(3), 299313, doi:10.1504/IJESB.2012.047437.

Markus, H. R., \& Kitayama, S. (1991). Culture and the self: Implications for cognition, emotion and motivation. Psychological Review, 98, 224-253.

Mcgrath, R. G., MacMillan, I. C., Yang, E. A., \& Tsai, W. (1992). Does Culture Endure, or Is It Malleable? Issues for Entrepreneurial Economic Development. Journal of Business Venturing, 7(6), 441-458.

Minkov, M., \& Hofstede, G. (2012). Is National Culture a Meaningful Concept?: Cultural Values Delineate Homogeneous National Clusters of In-Country Regions. Cross-Cultural Research, 46(2), 133-159, doi:10.1177/1069397111427262.

Minniti, M., Bygrave, W. D., \& Autio, E. (2006). GEM, Global Entrepreneurship Monitor, 2005 Executive Report. London, U.K. \& Babson Park, MA: London Business School \& Babson College.

Mueller, S. L., \& Thomas, A. S. (2001). Culture and entrepreneurial potential: A nine country study of locus of control and innovativeness. Journal of Business Venturing, 16(1), 51-75.

Mueller, S. L., Thomas, A. S., \& Jaeger, A. M. (2002). National entrepreneurial potential: the role of culture, economic development and political history. In M. A. Hitt, \& J. L. C. Cheng (Eds.), Managing Transnational Firms: Resources, Market Entry and Strategic Alliances (Vol. 14, pp. 221-257, Advances in International Management). Amsterdam: JAI Press.

Noorderhaven, N., Thurik, R., Wennekers, A. R. M., \& van Stel, A. (2004). The role of dissatisfaction and per capita income in explaining self-employment across 15 European countries. Entrepreneurship-Theory and Practice, 28(5), 447-466.

Parker, S. C., \& Robson, M. (2004). Explaining International Variations in Self-Employment: Evidence from a Panel of OECD Countries. Southern Economic Journal, 71(2), 287-301. 
Pinillos, M. J., \& Reyes, L. (2011). Relationship between individualist-collectivist culture and entrepreneurial activity: evidence from Global Entrepreneurship Monitor data. Small Business Economics, 37(1), 23-37, doi:10.1007/s11187-009-9230-6.

Reynolds, P. D., Bygrave, W., Autio, E., \& Hay, M. (2002). Global Entrepreneurship Monitor. 2002 summary report. Kansas City: Ewin Marion Kauffman Foundation.

Reynolds, P. D., Storey, D. J., \& Westhead, P. (1994). Cross-national comparison of the variation in new firm rates. Regional Studies, 28(4), 443-456.

Ros, M. (2002). Los valores culturales y el desarrollo socioeconómico: una comparación entre teorías culturales. Revista Española de Investigaciones Sociológicas, 99, 9-33.

Schwartz, S. H. (1992). Universals in the content and structure of values: Theoretical advances and empirical tests in 20 countries. In M. P. Zanna (Ed.), Advances in Experimental Social Pychology (Vol. 25, pp. 165). Nueva York: Academic Press.

Schwartz, S. H. (1994). Beyond Individualism-Collectivism: New cultural dimensions of values. In U. Kim, H. C. Triandis, C. Kagitçibasi, S. C. Choi, \& G. Yoon (Eds.), Individualism and collectivism. Theory, method, and applications (pp. 85-119). Thousand Oaks, CA: Sage.

Schwartz, S. H. (1999). Cultural value differences: some implications for work. Applied Psychology: An International Review, 48, 23-48.

Schwartz, S. H. (2004). Mapping and Interpreting Cultural Differences around the World. In H. Vinken, J. Soeters, \& P. Ester (Eds.), Comparing Cultures, Dimensions of Culture in a Comparative Perspective. Leiden, The Netherlands: Brill.

Schwartz, S. H. (2006a). Les valeurs de base de la personne : théorie, mesures et applications. Revue Francaise De Sociologie, 47(4), 929-968.

Schwartz, S. H. (2006b). A theory of cultural value orientations: explication and applications. Comparative Sociology, 5(2-3), 137-182, doi:http://dx.doi.org/10.1163/156913306778667357.

Schwartz, S. H. (2008). Cultural value orientations: Nature and implications of national differences. Moscow: Publishing House of SU HSE.

Schwartz, S. H., Melech, G., Lehmann, A., Burgess, S., \& Harris, M. (2001). Extending the cross-cultural validity of the theory of basic human values with a different method of measurement. Journal of CrossCultural Psychology, 32(5), 519-542.

Schwartz, S. H., \& Ros, M. (1995). Values in the West: A theoretical and empirical challenge to the Individualism-Collectivism cultural dimension. World Psychology, 1, 99-122.

Shane, S. (1993). Cultural Influences on National Rates of Innovation. Journal of Business Venturing, 8(1), 59-73.

Sternberg, R., \& Wennekers, A. R. M. (2005). Determinants and Effects of New Business Creation Using Global Entrepreneurship Monitor Data. Small Business Economics, 24(3), 193-203.

Tang, L., \& Koveos, P. E. (2008). A framework to update Hofstede's cultural value indices: Economic dynamics and institutional stability. Journal of International Business Studies, 39(6), 1045-1063.

Thornton, P. H., Ribeiro-Soriano, D., \& Urbano, D. (2011). Socio-cultural factors and entrepreneurial activity. International Small Business Journal, 29(2), 105-118, doi:10.1177/0266242610391930. 
Thurik, R., \& Dejardin, M. (2011). Entrepreneurship and Culture In M. Van Gelderen, \& E. Masurel (Eds.), Entrepreneurship in Context (pp. 175-186, Routledge Studies in Entrepreneurship). London: Routledge. van Stel, A., Carree, M., \& Thurik, R. (2005). The Effect of Entrepreneurial Activity on National Economic

Growth. Small Business Economics, 24(3), 311-321, doi:10.1007/s11187-005-1996-6.

van Stel, A., \& Storey, D. J. (2004). The Link Between Firm Births and Job Creation: Is there a Upas Tree

Effect? Regional Studies, 38(8), 893-909.

van Stel, A., Storey, D. J., \& Thurik, A. R. (2007). The effect of business regulations on nascent and young business entrepreneurship. [Article]. Small Business Economics, 28(2-3), 171-186.

van Stel, A., Wennekers, A. R. M., Thurik, A. R., \& Reynolds, P. (2003). Explaining nascent entrepreneurship across countries. SCALES-paper N2003-01. Zoetermeer: EIM Business and Policy Research.

Verheul, I., Wennekers, A. R. M., Audretsch, D. B., \& Thurik, A. R. (2002). An eclectic theory of entrepreneurship. In D. B. Audretsch, A. R. Thurik, I. Verheul, \& A. R. M. Wennekers (Eds.), Entrepreneurship: Determinants and Policy in a European-US Comparison. Boston/ Dordrecht: Kluwer Academic Publishers.

Weber, M. (1905). The Protestant Ethic and the Spirit of Capitalism. London \& Boston: Unwin Hyman. Wennekers, A. R. M., Thurik, R., van Stel, A., \& Noorderhaven, N. (2007). Uncertainty avoidance and the rate of business ownership across 21 OECD countries, 1976-2004. Journal of Evolutionary Economics, 17(2), 133-160.

Wennekers, A. R. M., Uhlaner, L. M., \& Thurik, A. R. (2002). Entrepreneurship and its conditions: A macro perspective. International Journal of Entrepreneurship Education, 1(1), 25-64.

Wennekers, A. R. M., van Stel, A., Thurik, A. R., \& Reynolds, P. D. (2005). Nascent Entrepreneurship and the Level of Economic Development. Small Business Economics, 24(3), 293-309.

\section{Appendix}

\section{List of countries (in brackets, years in which the SVS data were obtained)}

Argentina (1993, 1995), Australia (1988, 1990, 1992, 1996, 1999), Austria (1996, 1998), Belgium (1991, 1995, 2002), Bolivia (1993), Bosnia- Herzegovina (2002), Brazil (1989, 1991, 1993, 1995), Canada (1992, 2001, 2002), Chile (1994, 1995, 1997, 1998), China (1988, 1989, 1995), Costa Rica (2002, 2003), Croatia (2002), Denmark (1991, 1995), Egypt (2004), Finland (1989, 1991-1993, 1995, 1997, 1998, 2001), France 1991, 1994-1996, 1998), Germany (1989-1991, 1994, 1996), Ghana (1995), Greece (1989, 1996), Hong Kong (1988, 1996, 2001), Hungary (1990, 1995), India (1991, 1992), Indonesia (1992, 1995), Iran (2000), Ireland (1995, 2000), Israel (1989, 1990, 1994, 1995, 1996), Italy (1989, 1991, 1997, 2002), Japan (1989, 1990), Jordan (2002), Latvia (1998), Malaysia (1989, 2003), Mexico (1990, 1996), Netherlands 1988, 1996, 1998), New Zealand (1988, 1994, 1998), Norway (1994), Peru (1996, 2002, 2003), Philippines (1996, 1997, 2000), Poland (1988, 1990, 1997, 2003), Portugal (1989, 1993), Romania (1996), Russia (1993, 1995, 1996, 1999, 2002), Singapore (1991, 1995, 1997), Slovenia (1992), South Africa (1992, 1994, 1996, 2003), South Korea (1993, 2002), Spain (1988, 1996, 2002), Sweden (1992-1994, 1998), Switzerland (1990, 1996), Taiwan (1988, 1993, 1994), Thailand (2005), Turkey (1990, 1993, 1995, 2000), Uganda (1995), United Kingdom (1990, 1995), USA (1988, 1989, 1991-1996, 2000), Venezuela (1989, 1991, 1993, 1994), Yemen (2003). 
Figure 1. Cultural value dimensions

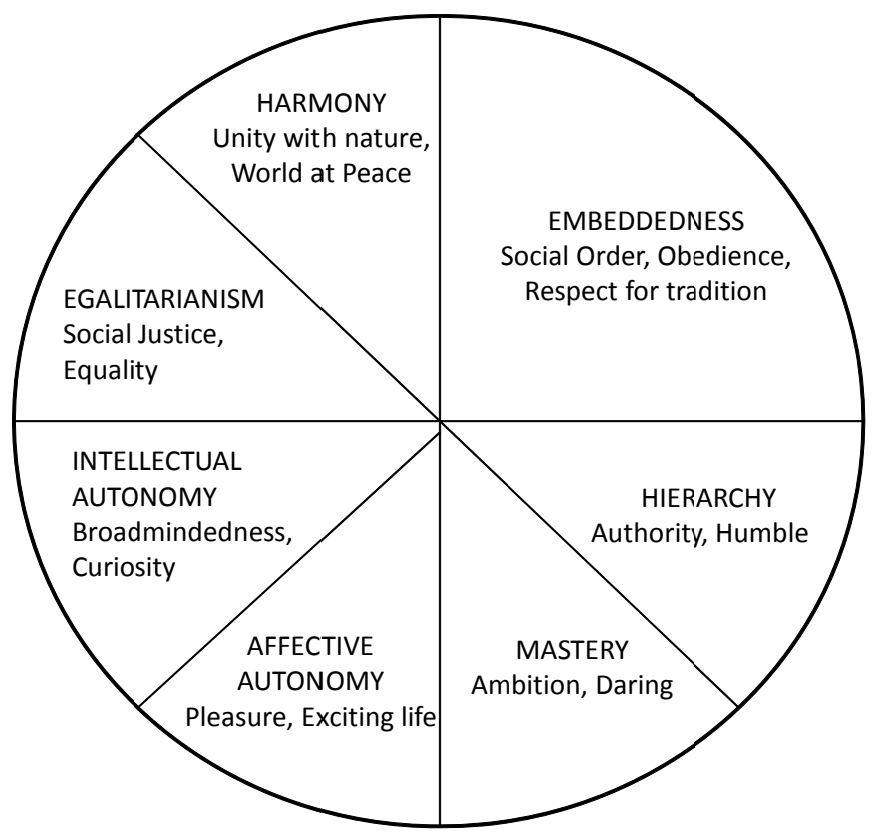

Source: Schwartz (2004)

Figure 2. Theoretical model and hypotheses

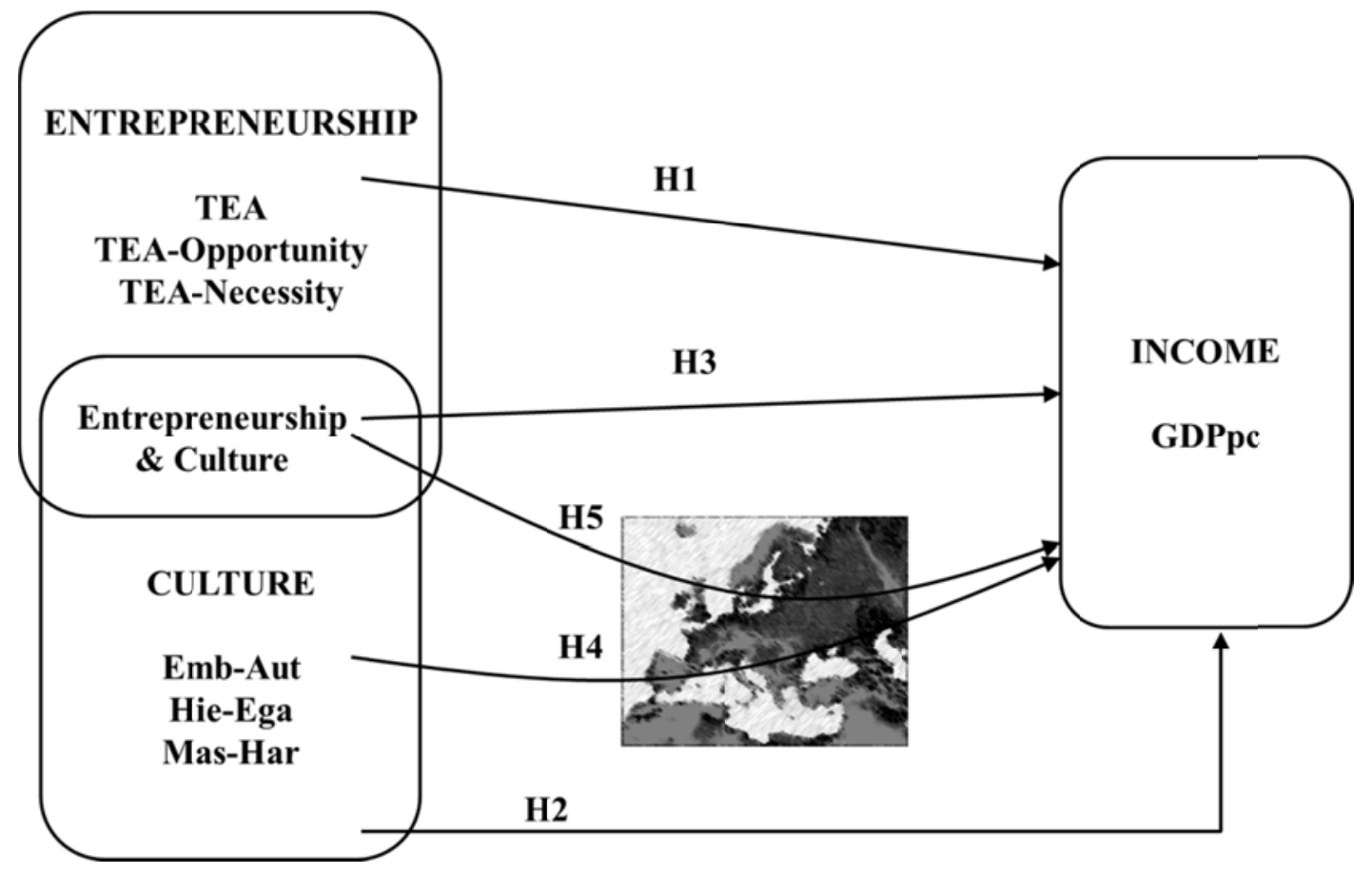


Figure 3: European Union clusters grouped by geographical areas

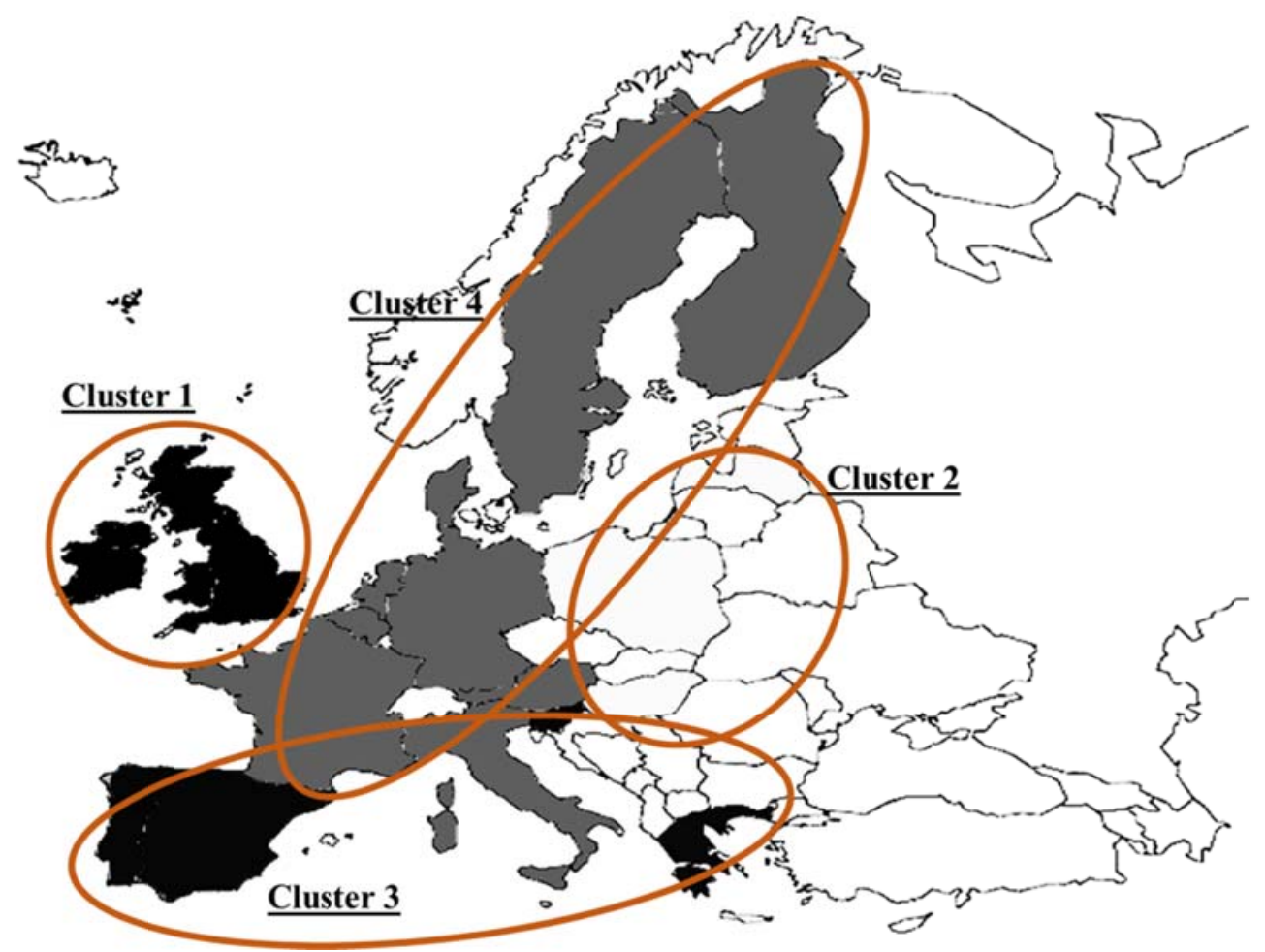

Table 1. Pearson's correlations

\begin{tabular}{|c|c|c|c|c|c|c|c|c|}
\hline & 1 & 2 & 3 & 4 & 5 & 6 & 7 & 8 \\
\hline 1 GDPpc & 1 & & & & & & & \\
\hline 2 TEA & $-0.615^{* *}$ & 1 & & & & & & \\
\hline 3 TEA-Necessity & $-0.437^{* *}$ & $0.888^{* *}$ & 1 & & & & & \\
\hline 4 TEA-Opportunity & $-0.689^{* *}$ & $0.909^{* *}$ & $0.762^{* *}$ & 1 & & & & \\
\hline 5 Emb-Auto & $-0.716^{* *}$ & $0.606^{* *}$ & $0.467^{* *}$ & $0.646^{* *}$ & 1 & & & \\
\hline 6 Hier-Egal & $-0.523^{* *}$ & $0.309^{*}$ & 0.239 & $0.405^{* *}$ & $0.579^{k *}$ & 1 & & \\
\hline 7 Mas-Har & -0.246 & 0.257 & 0.175 & $0.290^{*}$ & $0.310^{*}$ & $0.682^{* *}$ & 1 & \\
\hline 8 Mas-Har_Europe & $-0.435^{* *}$ & $0.323^{*}$ & 0.249 & $0.320^{*}$ & $0.372^{k *}$ & $0.561^{* *}$ & $0.651^{* *}$ & 1 \\
\hline
\end{tabular}


Table 2. Linear regression models for GDPpc based on entrepreneurial and cultural variables

\begin{tabular}{|c|c|c|c|c|c|}
\hline Variables & $\begin{array}{c}\text { Model } 1 \\
\beta\end{array}$ & $\begin{array}{c}\text { Model } 2 \\
\boldsymbol{\beta} \\
\end{array}$ & $\begin{array}{c}\text { Model } 3 \\
\boldsymbol{\beta} \\
\end{array}$ & $\begin{array}{c}\text { Model } 4 \\
\beta \\
\end{array}$ & $\begin{array}{c}\text { Model } 5 \\
\qquad \beta \\
\end{array}$ \\
\hline \multicolumn{6}{|c|}{ Entrepreneurship variables } \\
\hline TEA & $-0.615^{* * *}$ & $-0.326 * * *$ & $-0.301 * * *$ & $-0.687 * * *$ & $0.084 \mathrm{n} . \mathrm{s}$ \\
\hline TEA-Opportunity & & & & $0.397 * * *$ & \\
\hline TEA-Necessity & & & & & $-0.461 * * *$ \\
\hline \multicolumn{6}{|l|}{ Cultural variables } \\
\hline Emb-Auto & & $-0.390 * * *$ & $-0.375 * * *$ & $-0.319 * * *$ & $-0.337 * * *$ \\
\hline Hier-Egal & & $-0.314 * * *$ & $-0.281 * *$ & $-0.312 * * *$ & $-0.220 \mathrm{n} . \mathrm{s}$ \\
\hline Mas-Har & & $0.173 \mathrm{n} . \mathrm{s}$ & $0.288 * * *$ & $0.321 * * *$ & $0.283 * * *$ \\
\hline Mas-Har_Europe & & & $-0.228 * *$ & $-0.227 * *$ & $-0.250 * * *$ \\
\hline $\mathbf{R}^{2}$ & 0.378 & 0.602 & 0.629 & 0.660 & 0.661 \\
\hline Adjusted $\mathbf{R}^{2}$ & 0.367 & 0.570 & 0.592 & 0.619 & 0.620 \\
\hline F-statistic & $32.850 * * *$ & $19.245^{* * *}$ & $16.995^{* * *}$ & $15.883^{* * *}$ & $15.398 * * *$ \\
\hline
\end{tabular}

Dependent variable: GDPpc. Standardized $\beta$ coefficients shown.

Note: $n . s=$ not significant, ${ }^{*} \mathrm{p}<0.05,{ }^{* *} \mathrm{p}<0.01,{ }^{* * *} \mathrm{p}<0.001$.

Table 3. Cluster analysis for the European Union countries based on the GDPpc, entrepreneurship and cultural value dimensions.

\begin{tabular}{lccccccc}
\hline & $\begin{array}{c}\text { EU } \\
\text { average }^{\mathbf{a}}\end{array}$ & \multicolumn{5}{c}{ Cluster centers. } & \multicolumn{2}{c}{ ANOVA } \\
\cline { 2 - 8 } & & 1 & 2 & 3 & 4 & F & Sig. \\
\cline { 2 - 8 } GDPpc & $\mathbf{2 7 . 9 2}$ & 33.82 & 15.38 & 25.06 & 33.94 & 55.81 & 0.00 \\
Emb-Auto & $\mathbf{- 0 . 8 0}$ & -1.04 & -0.33 & -0.72 & -0.98 & 2.80 & 0.08 \\
Hier-Egal & $\mathbf{- 2 . 8 8}$ & -2.65 & -2.14 & -3.10 & -3.15 & 23.86 & 0.00 \\
Mas-Har & $\mathbf{- 0 . 3 4}$ & 0.24 & -0.25 & -0.44 & -0.52 & 3.13 & 0.06 \\
TEA & $\mathbf{5 . 3 8}$ & 7.17 & 6.89 & 5.79 & 4.41 & 10.01 & 0.00 \\
TEA-Opportunity & $\mathbf{2 . 9 0}$ & 3.91 & 3.44 & 3.19 & 2.55 & 3.26 & 0.05 \\
TEA-Necessity & $\mathbf{1 . 0 0}$ & 1.05 & 1.97 & 1.12 & 0.58 & 9.22 & 0.00 \\
\hline
\end{tabular}

${ }^{a}$ Average for the 19 EU countries included in the study

Table 4. EU Countries included in each cluster and corresponding geographical area

\begin{tabular}{ll}
\hline Cluster & Countries. \\
\hline 1 & United Kingdom, Ireland \\
2 & Hungary, Latvia, Poland \\
3 & Greece, Portugal, Slovenia; Spain \\
4 & Austria, Belgian, Denmark, Finland, Germany, Netherlands, Sweden, France, Italy. \\
\hline
\end{tabular}

